\title{
Assistenzhunde
}

\section{Vierbeiner geben neuen Lebensmut}

\author{
Der Verein VITA Assistenzhunde e. V. verhilft mit seinen Gefährten auf \\ vier Pfoten Menschen mit Behinderung zu mehr Lebensqualität. Für \\ dieses Engagement wurde der Verein mit dem 5. Preis des von Springer \\ Medizin vergebenen CharityAwards 2015 ausgezeichnet.
}

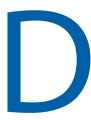
er kleine Can leidet aufgrund einer frühkindlichen Hirnschädigung an einer infantilen Zerebralparese. Nach einem schweren Unfall zieht er sich immer mehr in sich zurück. in sein Leben schleicht, findet Can neuen Lebensmut. Der Golden Retriever Mr. Winter ist ein Assistenzhund, den der Verein VITA der Familie von Can zur Seite stellt. Für ihren Einsatz zugunsten von Menschen mit Behinderungen hat der in Frankfurt am Main gegründete Verein den 5. Preis des von Springer Medizin vergebenen CharityAwards 2015 erhalten.

VITA Assistenzhunde e. V. wurde im März 2000 von Tatjana Kreidler ins Leben gerufen. Nachdem die Diplom-Sozialpädagogin in England bei Hilfsorganisationen eine Ausbildung zur Assistenzhundetrainerin absolviert hatte, war sie so begeistert von den Erfolgen der „Medizin auf vier Pfoten“, dass sie beschloss,

eine ähnliche Einrichtung in Deutschland zu gründen. Ziel ihres Vereins ist es, Menschen mit einer Behinderung zu mehr Unabhängigkeit, Lebensqualität und sozialer Integration zu verhelfen. Kinder und Jugendliche sollten dabei nicht ausgenommen werden. 2007 erhielt VITA Assistenzhunde als erster Verein auf dem europäischen Festland das Gütesiegel der Assistance Dogs Europe.

\section{Eingespieltes Team}

Can und Mr. Winter sind inzwischen ein eingespieltes Team. Der Retriever fördert und fordert den heute zwölfährigen Jungen tagtäglich. Durch den Umgang mit dem Assistenzhund hat sich Cans Feinmotorik verbessert, seine Konzentrationsfähigkeit ist ebenso gestiegen wie sein Selbstbewusstsein und seine Selbstständigkeit.

„Bis heute hat Can durch keine andere Therapie nur ansatzweise so viel gelernt Erst als sich Mr. Winter auf leisen Pfoten

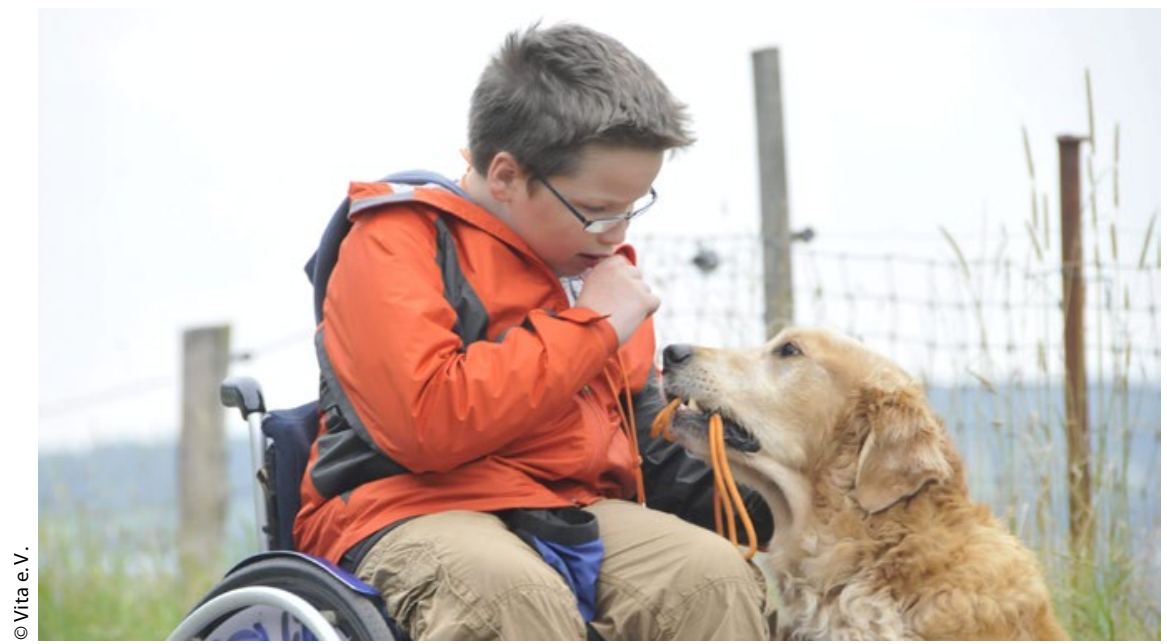

Ein Junge mit Behinderung und sein treuer vierbeiniger Freund, der das Wohlbefinden und das Selbstbewusstsein seines Partners steigert.

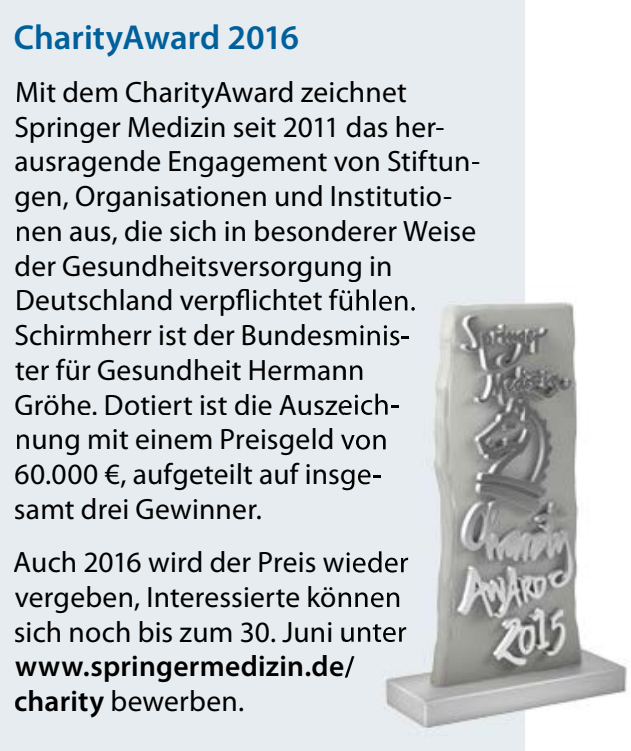

und sich erarbeitet wie mit Mr. Winter", sagt Cans Vater Thorsten Hormann. "Can weiß nun, dass er doch etwas kann.“ Tatsächlich bereichern die sorgfältig ausgewählten, bei Paten aufgezogenen und sozialisierten Hunde nicht nur das Leben vieler behinderter Menschen, sondern auch das von deren Familien. Die Hunde - Golden und Labrador Retriever - heben heruntergefallene Gegenstände auf, apportieren klingelnde Telefone, assistieren beim Ausziehen der Kleidung und holen im Notfall Hilfe. Daneben spenden sie Trost und fördern das Selbstbewusstsein ihres Partners sowie dessen Bereitschaft und Fähigkeit, Verantwortung zu übernehmen.

Derzeit, so Tatjana Kreidler, warten mehr als 100 Interessenten auf einen Assistenzhund von VITA. Allerdings schlagen Anschaffung, Ausbildung und Zusammenführung eines einzigen Assistenzhundes mit etwa $25.000 € \mathrm{zu} \mathrm{Bu}$ che. Der Verein trägt die Hauptkosten selbst. Er finanziert sich ausschließlich aus Spenden, Fördermitteln und über Sponsoren.

Pete Smith 